\title{
Control of Magnesium-Protoporphyrin Chelatase Activity in Rhodopseudomonas spheroides
}

\author{
ROLE OF LIGHT, OXYGEN, AND ELECTRON AND ENERGY TRANSFER
}

\author{
By ABEL GORCHEIN \\ Department of Chemical Pathology and Medical Unit, St. Mary's Hospital Medical School, \\ London, W.2, U.K.
}

(Received 18 October 1972)

\begin{abstract}
1. Magnesium-protoporphyrin chelatase activity, previously shown in whole cells of Rhodopseudomonas spheroides, could not be demonstrated in cell-free extracts prepared in different ways, although spheroplasts retained moderate activity. Slight activity was detected also in whole cells of Rhodospirillum rubrum. 2 . The effects on the activity of the enzyme of inhibitors of electron and energy transfer were studied in whole cells of Rps. spheroides. Amytal, rotenone, azide and cyanide inhibited at low $p \mathrm{O}_{2}$ in the dark but not under anaerobic conditions in the light. Antimycin A and 2-heptyl-4-hydroxyquinoline $\mathrm{N}$-oxide, as well as uncouplers and oligomycin, inhibited under all environmental conditions. 3. The effects on magnesium chelatase activity of intermediates of the tricarboxylic acid cycle, of thenoyltrifluoroacetone, of a number of artificial electron donors or acceptors, of various quinones and of the oxidation-reduction indicator dyes Benzyl Viologen and Methyl Viologen are described. 4. It was concluded that electron transport between a $b$-type and a $c$-type cytochrome as well as associated energy conservation and transformation reactions were essential for activity. There was also a specific requirement for ATP. 5. Exogenous protoporphyrin and magnesium protoporphyrin monomethyl ester were incorporated into bacteriochlorophyll or late precursors by whole cells. 6 . Evidence is presented that the insertion of magnesium was the only step inhibited by oxygen in the biosynthetic pathway between protoporphyrin and bacteriochlorophyll.
\end{abstract}

It has recently been shown that whole cells of Rhodopseudomonas spheroides can incorporate magnesium into exogenous protoporphyrin (Gorchein, 1972). This chelation of magnesium was obligatorily coupled with methylation of the protoporphyrin, so that magnesium protoporphyrin monomethyl ester was formed, and this coupling could be explained if a multienzyme complex were responsible for the overall reaction. The insertion of magnesium anaerobically required light, and in the dark it was dependent on the presence of oxygen at a low partial pressure.

The present communication extends these earlier studies and describes attempts to demonstrate activity in cell-free systems prepared in various ways. The effects of inhibitors of electron and energy transfer on magnesium chelatase activity in whole cells are reported. The chelation of magnesium appears to require electron transport and the associated energy conservation and transformation reactions.

This paper also reports the incorporation of exogenous protoporphyrin and magnesium protoporphyrin monomethyl ester into bacteriochlorophyll by whole cells of Rps. spheroides and the detection of magnesium chelatase activity in Rhodospirillum rubrum.

\section{Materials and Methods}

\section{Chemicals}

2,4-Dinitrophenol, 2,4-dibromophenol, rotenone, 4,4,4-trifluoro-1-(2-thienyl)-1,3-butanedione (thenoyltrifluoroacetone), $\quad N N N^{\prime} N^{\prime}$-tetramethyl-p-phenylenediamine dihydrochloride, Benzyl Viologen, Methyl Viologen, sodium monofluoroacetate and polyethylene powder were obtained from British Drug Houses Ltd., Poole, Dorset, U.K. Dicoumarol, oligomycin, antimycin A, 2-heptyl-4-hydroxyquinoline $N$ oxide, phenazine methosulphate, lysozyme and deoxyribonuclease were obtained from Sigma (London) Chemical Co., London S.W.6, U.K. ATP, NAD ${ }^{+}$, NADH, NADP ${ }^{+}, \mathrm{NADPH}$ and $\alpha$-oxoglutarate were from Boehringer, Mannheim, Germany. Carbonyl cyanide $m$-chlorophenylhydrazone was from $\mathrm{Cal}$ biochem, Los Angeles, Calif., U.S.A. 2,3,5,6-Tetramethyl-1,4-benzoquinone (duroquinone) and 5-hydroxy-1,4-naphthaquinone (juglone) were obtained from R. N. Emanuel Ltd., Wembley, Middx., U.K. 2-Methyl-1,4-naphthaquinone and 2-methyl-3-phytyl-1,4-naphthaquinone were from Roche Products Ltd., Welwyn Garden City, Herts., U.K. Sodium Amytal was from E. Lilly and Co., Basingstoke, 
Hants., U.K. $S$-Adenosyl-L-[Me- $\left.{ }^{14} \mathrm{C}\right] \mathrm{methionine}$ (sp. radioactivity $58 \mathrm{mCi} / \mathrm{mmol})$ and $\left[2-{ }^{14} \mathrm{C}\right]$ glycine $(\mathrm{sp}$. radioactivity $57 \mathrm{mCi} / \mathrm{mmol}$ ) were obtained from The Radiochemical Centre, Amersham, Bucks., U.K. 3,5-Diethoxycarbonyl-1,4-dihydro-2,4,6-trimethylpyridine was synthesized by the method of De Matteis \& Prior (1962).

$\left[{ }^{14} \mathrm{C}\right]$ Protoporphyrin was obtained as follows: 3,5-diethoxycarbonyl-1,4-dihydro-2,4,6-triemthylpyridine $(7.5 \mathrm{mg}$ in $0.2 \mathrm{ml}$ of an aqueous suspension with Tween 80 ) was given daily by intraperitoneal injection for 7 days to a male Wright-Fleming strain mouse weighing $30 \mathrm{~g}$ (cf. Onisawa \& Labbe, 1963). Starting on the second day, $5 \mu \mathrm{Ci}$ of $\left[2-{ }^{14} \mathrm{C}\right]$ glycine (sp. radioactivity $57 \mathrm{mCi} / \mathrm{mmol}$ ) was also injected for 6 days. Food and water were given $a d$ lib. The faeces were collected for 9 days and the protoporphyrin was extracted with ethyl acetate-acetic acid $(3: 1, \mathrm{v} / \mathrm{v})$ and purified by standard methods (Falk, 1964). The radiochemical purity was confirmed by t.l.c. in 2,6lutidine-water in an atmosphere of $\mathrm{NH}_{3}$ (Kehl \& Stich, 1951). The specific radioactivity was $66 \mathrm{c.p.m} . /$ nmol at a counting efficiency of $80 \%$. The sources of other chemicals were as described previously (Gorchein, 1972) or were of the purest grades available commercially.

\section{Organisms and cell fractionation}

Organisms. Rhodopseudomonas spheroides and Rhodospirillum rubrum were grown and harvested as described previously (Gorchein, 1972).

Methods of cell disruption. Cells were suspended to a final concentration of $25 \mathrm{mg}$ dry $\mathrm{wt}$. $/ \mathrm{ml}$ in ion-free water, in $0.1 \mathrm{M}$-Tris- $\mathrm{HCl}$ buffer, $\mathrm{pH} 8.6$, or in this buffer solution containing $20 \mathrm{~mm}$-ethanedioxybis(ethylamine)tetra-acetate (EGTA) or one of the chelators previously described (Gorchein, 1972). These suspensions were treated in different ways.

1. Micro-organisms were disrupted by a single passage through a French pressure cell at either $140 \mathrm{MPa}\left(20000 \mathrm{lb} / \mathrm{in}^{2}\right)$ or at $42 \mathrm{MPa}\left(6000 \mathrm{lb} / \mathrm{in}^{2}\right)$.

2. Suspensions were mixed with an equal volume of $0.1 \mathrm{~mm}$ glass beads and treated in a Braun shaker for periods of up to $2 \mathrm{~min}$.

3. Cells suspended in the buffer-chelator mixture were incubated at $35^{\circ} \mathrm{C}$ for different times after addition of lysozyme $(40-60 \mu \mathrm{g} / \mathrm{ml})$. In some experiments this was followed by incubation for $15 \mathrm{~min}$ with deoxyribonuclease $(20 \mu \mathrm{g} / \mathrm{ml})$.

4. Portions $(2 \mathrm{ml})$ of the suspensions were kept cool by immersing the tube in crushed ice and were irradiated for different times at maximum power in an MSE ultrasonic power unit $(50 \mathrm{~W})$ in bursts of 30 s, with 30 s rest periods.

Preparation of 'pellet' and 'supernatant' fractions. Cell extracts prepared by the different methods were centrifuged in the SW39 rotor of a Spinco model L ultracentrifuge for $15 \mathrm{~s}$ at $20000 \mathrm{~g}$ as follows. The rotor was accelerated to $5000 \mathrm{rev}$./min within about 10 s by gradually turning up the speed-control dial. This was then set at $35000 \mathrm{rev} . / \mathrm{min}$ and when the rotor had reached $15000 \mathrm{rev} . / \mathrm{min}(20000 \mathrm{~g})$ the dial was turned down to this speed. After $15 \mathrm{~s}$, the timecontrol was turned to zero and deceleration was allowed to take place with the brake 'on'. The 'supernatant' was put aside and the 'pellet' was taken up in ion-free water, in buffer solution or in bufferchelator mixture and homogenized by sucking up and down in a Pasteur pipette.

Determination of numbers of whole cells. After appropriate dilution of cell suspensions or of extracts or pellets with $0.9 \% \mathrm{NaCl}$ (Polyfusor; Boots Pure Drug Co. Ltd., Nottingham, U.K.), cell numbers were determined in a Coulter counter, model $F_{N}$, fitted with a $30 \mathrm{~nm}$ aperture and operated at an attenuation of 0.125 and an aperture current of ' 8 '.

\section{Assays of activity}

Magnesium-protoporphyrin chelatase. This was done by extracting and determining the magnesium protoporphyrin monomethyl ester formed in a previous incubation as described by Gorchein (1972), but extraction of the buffer solutions with dithizone (diphenylthiocarbazone) was found to be unnecessary.

$S$-Adenosylmethionine-magnesium protoporphyrin methyltransferase.(i) Whole cells. The activity of this enzyme was determined essentially as described for the assay of magnesium-protoporphyrin chelatase, but the substrate was magnesium protoporphyrin suspended in lipid sol. Other modifications were as follows. On shaking with ether at $\mathrm{pH} 7.5$, significant amounts of magnesium protoporphyrin were extracted in addition to the magnesium protoporphyrin monomethyl ester. The ether extract was therefore 'washed' three times by shaking with $1 \mathrm{ml}$ portions of ion-free water, which removed most of the magnesium protoporphyrin into the aqueous phase. After this third wash, the aqueous phase was free of fluorescence, indicating that no further extraction of magnesium protoporphyrin was taking place. The ether phase, however, still contained various amounts $(10-30 \%)$ of magnesium protoporphyrin, as determined by the t.l.c. system described previously (Gorchein, 1972). Accordingly, the assay was performed after adding substrate amounts $(200 \mathrm{nmol})$ of $\mathrm{L}-\left[\mathrm{Me}^{-14} \mathrm{C}\right]$ methionine (sp. radioactivity $0.5 \mathrm{mCi}$ / $\mathrm{mmol})$. From the known specific radioactivity of the added $\mathrm{L}-\left[\mathrm{Me}^{14}{ }^{14} \mathrm{C}\right]$ methionine and the radioactivity incorporated into the washed ether phase, the amount of magnesium protoporphyrin monomethyl ester was determined.

(ii) Cell-free extracts. The activity was assayed as in the whole cells except that $150 \mathrm{nmol}$ of $S$-adenosyl- 
$\mathrm{L}-\left[\mathrm{Me}-{ }^{14} \mathrm{C}\right]$ methionine (sp. radioactivity $0.66 \mathrm{mCi} /$ mmol) was added (cf. Gibson et al., 1963).

\section{Other techniques}

Conditions of incubation at controlled partial pressures of oxygen. Controlled-atmosphere chambers were constructed from glass ointment jars 4 in wide and 3 in high. The Bakelite lids were drilled to take two rubber bungs carrying glass inlet and outlet tubes respectively. The chambers were made gas-tight by fitting the screw-on lid with a rubber gasket and coating with silicone grease. A circular aluminium rack fitted tightly inside each jar and the reaction vessels ( $5 \mathrm{ml}$ conical flasks) were suspended from it and held in position by circular springs placed over their necks. Water was placed in the chambers so that the suspended flasks were partly immersed and the whole assembly was shaken at maximum speed in a Gallenkamp Shaking Reaction Incubator at $35^{\circ} \mathrm{C}$. Humidified mixtures of $\mathrm{O}_{2}$ and $\mathrm{N}_{2}$ were prepared by passing appropriate volumes of each from cylinders (Air Products) through gas-dispersion tubes into water in a mixing vessel fitted with a single outlet tube. This latter was connected to the inlet tube of the controlledatmosphere chamber. The gas flow rates were regulated by passage through needle-valves (Griffin and George, London, U.K.) and measured with Rotameter flow gauges (Rotameter Co. Ltd., Croydon, Surrey, U.K.). In general, the flow rate of $\mathrm{N}_{2}$ was kept at $1000 \mathrm{ml} / \mathrm{min}$ and the flow of $\mathrm{O}_{2}$ was varied to give the required partial pressure. Illumination, where indicated, was supplied by two banks of three $60 \mathrm{~W}$ lamps supported on top of the shaking bath.

Measurement of uptake of oxygen. This was done in a Clark-type oxygen electrode (Rank Brothers, Bottisham, Cambridge, U.K.) fitted with a Hitachi Perkin-Elmer recorder, model 165 . Reaction mixtures contained $100 \mu \mathrm{mol}$ of Tris buffer, pH8.6, $20 \mu \mathrm{mol}$ of trans-1,2-diaminocyclohexanetetra-acetate, $2.5-10 \mathrm{mg}$ dry wt. of semi-anaerobically grown cells and ion-free water saturated with air, or with mixtures of $\mathrm{O}_{2}+\mathrm{N}_{2}(10: 90$, or 5:95), to a final volume of $0.95 \mathrm{ml}$. Illumination was provided when required by a $12 \mathrm{~V}, 21 \mathrm{~W}$, bulb, $5 \mathrm{~cm}$ from the clear Perspex side of the oxygen electrode.

Uptake of protoporphyrin by whole cells. Incubations were set up as described above for the assay of magnesium-protoporphyrin chelatase. After different times the reaction mixtures were layered on top of $3 \mathrm{ml}$ of a solution of Ficoll (Pharmacia Fine Chemicals), $10 \%(\mathrm{w} / \mathrm{v})$ in $0.05 \mathrm{~m}$-Tris, $\mathrm{pH}$ 8.6. The tubes were centrifuged in the SW39L rotor of the Spinco ultracentrifuge at $20000 \mathrm{rev} . / \mathrm{min}(33000 \mathrm{~g})$ for $5 \mathrm{~min}$, including the time taken to reach this speed. The supernatants were discarded and the pellets of whole cells were resuspended in $3 \mathrm{ml}$ of the Ficoll-Tris mixture and were centrifuged again under the same conditions. The pellets were then homogenized by sucking up and down with a Pasteur pipette in $0.5 \mathrm{ml}$ of lipid sol and the suspensions were layered on top of $3 \mathrm{ml}$ of Ficoll-Tris and centrifuged as before. The pellets were sonicated for $90 \mathrm{~s}$ after addition of $0.5 \mathrm{ml}$ of $0.1 \mathrm{M}$-Tris buffer, $\mathrm{pH} 8.6$. Extraction and determination of magnesium protoporphyrin monomethyl ester and of protoporphyrin were done as described previously (Gorchein, 1972). This method was used since single-step filtration-centrifugation (cf. Klingenberg \& Pfaff, 1967) did not separate extracellular from intracellular protoporphyrin, for reasons described below.

\section{Results}

Attempts to demonstrate magnesium-protoporphyrin chelatase activity in cell-free extracts

A progressive loss of activity of magnesium-protoporphyrin chelatase was found with increasing time of ultrasonic disruption of the cells (Fig. 1). The whole sonicate, however, was more active than the 'pellet'.

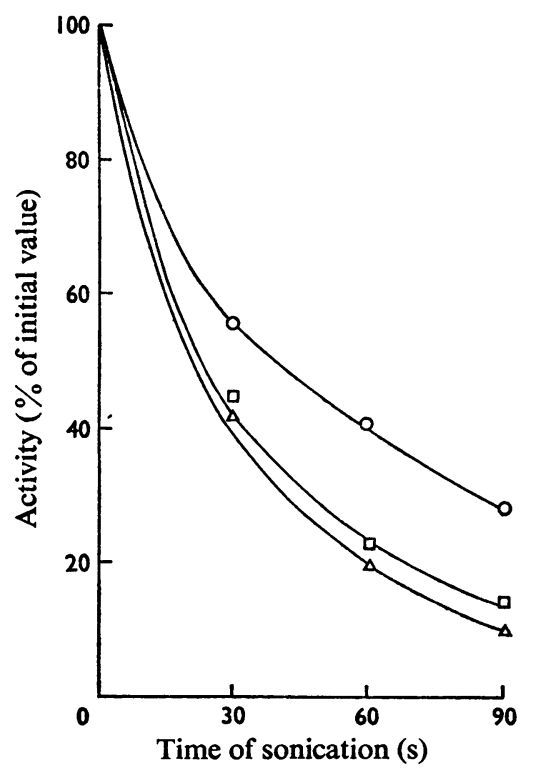

Fig. 1. Relation between time of ultrasonic disruption of Rhodopseudomonas spheroides and activity of magnesium chelatase

The cells were suspended in ion-free water at a concentration of $25 \mathrm{mg}$ dry wt. $/ \mathrm{ml}$. Disruption of the cells and assay of magnesium chelatase activity in the whole sonicate $(O)$ and in the pellet $(\square)$ were done as described in the Materials and Methods section. Cell numbers $(\Delta)$ were determined with a Coulter counter. 


\section{Table 1. Magnesium-protoporphyrin chelatase activity in sonicated extracts of Rhodopseudomonas spheroides}

Portions of cells $(2 \mathrm{ml})$ suspended in ion-free water at a concentration of $25 \mathrm{mg}$ dry wt./ $\mathrm{ml}$ were disrupted by ultrasonic irradiation for $90 \mathrm{~s}$ and the extract was then centrifuged to give pellet and supernatant fractions as described in the Materials and Methods section. The pellet was resuspended to $1.0 \mathrm{ml}$ with ion-free water. Assays were done as described previously (Gorchein, 1972) but with $0.4 \mathrm{ml}$ of whole sonicate or of supernatant, or with $0.2 \mathrm{ml}$ of pellet samples. The final volume in each assay was made up to $0.9 \mathrm{ml}$ with ion-free water.

Tube no.

1 Whole sonicate

2

3

4

5

Pellet

Supernatant
Fraction assayed

Pellet + supernatant

Pellet $+S$-adenosylmethionine (1 mM)
Magnesium protoporphyrin monomethyl ester (nmol/assay)

10.8

5.3

0.0

9.0

7.1
The 'supernatant' fraction, which contained pigmented small particles or chromatophores, was completely inactive, but when added back to the 'pellet' it restored the activity to the value given by the whole extract (Table 1). This activation was due to small molecules, since it was lost after dialysis of the 'supernatant'. Some activation of the 'pellet' was obtained by adding high concentrations of $S$-adenosylmethionine (Table 1). It was likely therefore that only part of the activation by the 'supernatant' was due to its content of $S$-adenosylmethionine and that other molecules of low molecular weight were also involved.

Extracts prepared by disrupting micro-organisms in the French pressure cell had no magnesium protoporphyrin chelatase activity, whether assayed anaerobically in the light or at low partial pressures of oxygen in the dark. Cells disrupted for $2 \mathrm{~min}$ with $0.1 \mathrm{~mm}$ glass beads in a Braun shaker were also completely inactive. Shorter times of shaking gave some activity, but this was proportional to the quantity of intact cells remaining.

None of these conditions of cell breakage inhibited $S$-adenosylmethionine-magnesium protoporphyrin methyltransferase in the 'supernatant' fraction.

In view of these findings, it was thought that cell disruption by gentler methods would be required to demonstrate magnesium chelation. Cells were incubated with lysozyme as described in the Materials and Methods section. After about $30 \mathrm{~min}$ the reaction mixtures had become extremely viscous, but less turbid, and microscopy confirmed that the cells had been converted into spheroplasts, some of which were lysed. To test whether magnesium chelatase activity could still be demonstrated at this stage, organisms were 'preincubated' for different times with lysozyme and the complete reaction mixture, but without lipid-protoporphyrin. This substrate was then added and the activity of magnesium-protoporphyrin chelatase was determined in the usual way. A progressive loss of activity was found with the time of preincubation. After $30 \mathrm{~min}$, the activity was still usually more than $90 \%$ of the original, but it fell markedly after $1 \mathrm{~h}$. After the preparation was separated into 'supernatant' and 'pellet' fractions by centrifuging, the residual activity was confined to the 'pellet'. Further incubation of this fraction with its 'supernatant' resulted in loss of activity, presumably because of the continued action of lysozyme. The 'pellet' fraction, however, was activated by the addition of $S$-adenosylmethionine or by incubation with a 'supernatant' fraction from cells disrupted by sonication. Even gentle homogenization of the spheroplasts in a hand-operated all-glass homogenizer, or lysis with ion-free water, resulted in complete loss of activity, which could not be restored by the addition of 'supernatant' or of $S$-adenosylmethionine, ATP and nicotinamide-adenine dinucleotides.

Since no evidence for cell-free activity could be obtained, further studies were done with whole cells in the hope that the loss of activity of magnesium chelatase on cell-breakage could be explained.

\section{Activity of magnesium-protoporphyrin chelatase in whole cells}

Influence of ionic strength. Magnesium-protoporphyrin chelatase was inhibited by about $70 \%$ by increasing the ionic strength of the incubation medium to 0.23 with either Tris buffer or $\mathrm{NaCl}$, but decreasing the ionic strength below that originally described $(I=0.11)$ did not give increased activity in Rps. spheroides. At 10.022, however, with 20 mM-Trischloride buffer, pH8.6, and 4mm-trans-1,2-diaminocyclohexanetetra-acetate, activity was demonstrated in $R$. rubrum. The highest activity was about $20 \%$ of that found in Rps. spheroides and was obtained at low partial pressure of oxygen in the dark $\left(\mathrm{O}_{2}+\mathrm{N}_{2}\right.$; 5:95), This was nearly double the activity under anaerobic conditions in the light. The reasons for these differences are not clear, but it is noteworthy that a relatively minor change in the conditions has 
Table 2. Effect of inhibitors of electron and energy transfer on the activity of magnesium chelatase and on oxygen uptake with whole cells of Rhodopseudomonas spheroides

Magnesium chelatase was assayed as described in the Materials and Methods section. Inhibitors were added in $5 \mu \mathrm{l}$ of ethanol or in water as appropriate and were incubated with the cells for $5 \mathrm{~min}$ before addition of the substrate. Oxygen uptake was determined in an oxygen electrode as described in the Materials and Methods section. Rates of uptake without inhibitors were between 7 and $10 \mathrm{nmol} / \mathrm{min}$ per $\mathrm{mg}$ dry wt. of cells. Abbreviations: CCCP, carbonyl cyanide $m$-chlorophenylhydrazone; HOQNO, 2-heptyl-4-hydroxyquinoline $\mathrm{N}$-oxide.

\begin{tabular}{|c|c|c|c|}
\hline \multirow[b]{2}{*}{ Additions to assay } & \multicolumn{2}{|c|}{$\begin{array}{c}\text { Magnesium protoporphyrin } \\
\text { monomethyl ester (nmol) }\end{array}$} & \multirow[b]{2}{*}{$\begin{array}{l}\text { Uptake of } \mathrm{O}_{2} \\
\text { (\% of control }\end{array}$} \\
\hline & $\begin{array}{l}\text { Anaerobic/ } \\
\text { light }\end{array}$ & $\begin{array}{c}\mathrm{O}_{2}+\mathrm{N}_{2} \\
(5: 95) / \text { dark }\end{array}$ & \\
\hline None & 13.1 & 14.1 & 100 \\
\hline Ethanol & 14.0 & 13.2 & 100 \\
\hline $5 \mathrm{~mm}$-Amytal & 15.2 & 4.7 & 26 \\
\hline $10 \mathrm{~mm}-$ Amytal & 8.1 & 0.7 & \\
\hline $0.1 \mathrm{~mm}$-Rotenone & 13.7 & 5.5 & 36 \\
\hline $30 \mu \mathrm{M}-$ Antimycin A & 7.1 & 8.0 & 40 \\
\hline $50 \mu \mathrm{M}-$ Antimycin A & 1.3 & 1.8 & 15 \\
\hline $90 \mu \mathrm{M}-\mathrm{HOQNO}$ & 1.5 & 1.7 & 19 \\
\hline $1 \mathrm{mM}-\mathrm{NaN}_{3}$ & 12.9 & 4.3 & 35 \\
\hline $4 \mathrm{~mm}-\mathrm{KCN}$ & 14.0 & 1.5 & 5 \\
\hline $16 \mathrm{~mm}-\mathrm{KCN}$ & 13.2 & 1.6 & \\
\hline $1 \mathrm{~mm}-2,4-$ Dinitrophenol & 1.0 & 2.3 & \\
\hline $0.85 \mathrm{~mm}-2,4-D i b r o m o p h e n o l$ & 1.2 & 1.3 & 70 \\
\hline $0.2 \mathrm{~mm}$-Dicoumarol & 0.8 & 1.0 & 120 \\
\hline $8 \mu \mathrm{M}-\mathrm{CCCP}$ & 6.5 & 6.9 & 144 \\
\hline $50 \mu \mathrm{M}-\mathrm{CCCP}$ & 1.2 & 1.4 & 90 \\
\hline $0.2 \mathrm{~mm}$-Oligomycin & 6.2 & 7.3 & \\
\hline $0.27 \mathrm{~mm}$-Oligomycin & 0.9 & 1.9 & \\
\hline $5 \mathrm{~mm}$-Arsenate & 9.3 & 10.0 & \\
\hline
\end{tabular}

enabled magnesium chelatase activity to be detected in $R$. rubrum. The inhibition at high ionic strength may be due to aggregation of the protoporphyrin and may not be directly related to the activity of the enzyme.

All the further experiments described were done with Rps. spheroides and care was taken not to increase the final ionic strength to the point of significant inhibition.

Effect of inhibitors of electron and energy transfer. Amytal inhibited magnesium chelation at low partial pressures of oxygen in the dark at concentrations that were not inhibitory under anaerobic conditions in the light (Table 2), and a similar effect was noted with rotenone. Antimycin A and 2-alkyl-4-hydroxyquinoline $N$-oxide inhibited magnesium chelation under all conditions of incubation. The reaction was inhibited by $50 \%$ by $30 \mu \mathrm{M}$-antimycin, but stimulation by up to $20 \%$ was noted between 2 and $20 \mu \mathrm{M}$. Potassium cyanide and sodium azide inhibited the formation of magnesium protoporphyrin monomethyl ester at low partial pressure of oxygen in the dark but not under anaerobic conditions in the light. At the concentrations used all these compounds inhibited respiration at low partial pressure of oxygen in the dark (Table 2) to about the same extent that they inhibited magnesium chelation.

The uncouplers 2,4-dinitrophenol, 2,4-dibromophenol, carbonyl cyanide $m$-chlorophenylhydrazone and dicoumarol inhibited magnesium chelatase activity under both anaerobic conditions in the light and also at low partial pressures of oxygen in the dark (Table 2). The reaction was particularly sensitive to carbonyl cyanide $m$-chlorophenylhydrazone, which inhibited by $50 \%$ at about $7.5 \mu \mathrm{M}$. Marked inhibition was produced also by oligomycin. The relatively high concentration required may be due to its low permeability. Arsenate inhibited by only about $25 \%$ even at $5 \mathrm{~mm}$, probably because of the high intracellular content of $\mathbf{P}_{\mathbf{i}}$. The uncouplers increased or decreased the initial respiratory rate, depending on their concentrations. In addition they prevented the inhibition of oxygen uptake that normally occurs on illuminating whole cells of Rps. spheroides. This wellknown effect of light (e.g. Van Niel, 1941) has been attributed to competition for carriers of the 'respiratory' and 'photosynthetic' electron-transport chain. Effects of thenoyltrifluoroacetone. Magnesium 
chelatase was inhibited under both anaerobic conditions in the light and also at low partial pressure of oxygen in the dark by thenolytrifluoroacetone $(50 \%$ inhibition at $0.2 \mathrm{~mm}$ ). This concentration did not significantly inhibit uptake of oxygen, which was, however, decreased by $50 \%$ with $1.5 \mathrm{~mm}$. Although the effect on oxygen uptake of inhibiting succinate dehydrogenase might be obscured by high activity of NADH oxidase, other possibilities were considered. In view of its structural resemblance to pyrrole, thenoyltrifluoroacetone was tested as a competitive inhibitor of protoporphyrin. It was found (Fig. 2) that the inhibitory effect of $0.25 \mathrm{~mm}$-thenoyltrifluoroacetone was not relieved by increasing the concentration of protoporphyrin in the assay and, in addition, the stimulation by lower concentrations was greatest with the lower amounts of substrate (Fig. $2 b$ ). Thus $125 \mu \mathrm{M}$-thenoyltrifluoroacetone stimulated with substrate concentrations of up to $80 \mu \mathrm{M}$, but at $120 \mu \mathrm{M}$ it inhibited. This effect of abolishing the $\mathrm{S}$ shape of the substrate curve is similar to that found previously by adding lipid sol to the assay system (Fig. 4 of Gorchein, 1972).

Effect of artificial electron donors or acceptors. Tetramethyl-p-phenylenediamine and $N$-methylphenazonium methosulphate inhibited magnesium chelation (Fig. 3), the former compound being more effective, inhibiting by $50 \%$ at about $6 \mu \mathrm{M}$. With lower concentrations stimulation was obtained. Addition of $N$-methylphenazonium methosulphate at non-inhibitory concentrations, either alone or with ascorbate, did not restore magnesium chelation in the assay system inhibited by antimycin or 2-alkyl-4hydroxyquinoline $N$-oxide, although oxygen uptake was restored to about $80 \%$ of the original rate. This artificial electron-donor system has been used to bypass the cytochrome $b \rightarrow$ cytochrome $c$ site blocked by these compounds (see, e.g., Lee et al., 1965) and it was verified that in the present experiments the oxygen uptake in the presence of tetramethyl-p-phenylenediamine was completely inhibited by KCN.

$A$ number of quinones and vitamin $\mathrm{K}$ analogues also inhibited or stimulated magnesium chelation (Table 3). 2,3,5,6-Tetramethyl-1,4-benzoquinone (duroquinone) stimulated by up to $80 \%$ at $0.1 \mathrm{~mm}$, particularly under anaerobic conditions in the light, but juglone, which stimulated in the range $2-20 \mu \mathrm{M}$, inhibited by about $85 \%$ at $60 \mu \mathrm{M}$. The effects of the oxidation-reduction indicator dyes Benzyl and Methyl Viologen under anaerobic conditions in the light are shown in Fig. 4. Some stimulation was produced by Benzyl Viologen at concentrations of up to about $35 \mu \mathrm{M}$, but higher concentrations inhibited. Methyl Viologen, however, stimulated markedly over an extremely wide concentration range, the activity not being inhibited even by $5 \mathrm{~mm}$. Under photosynthetic conditions Methyl Viologen stimulated at different substrate concentrations and rendered
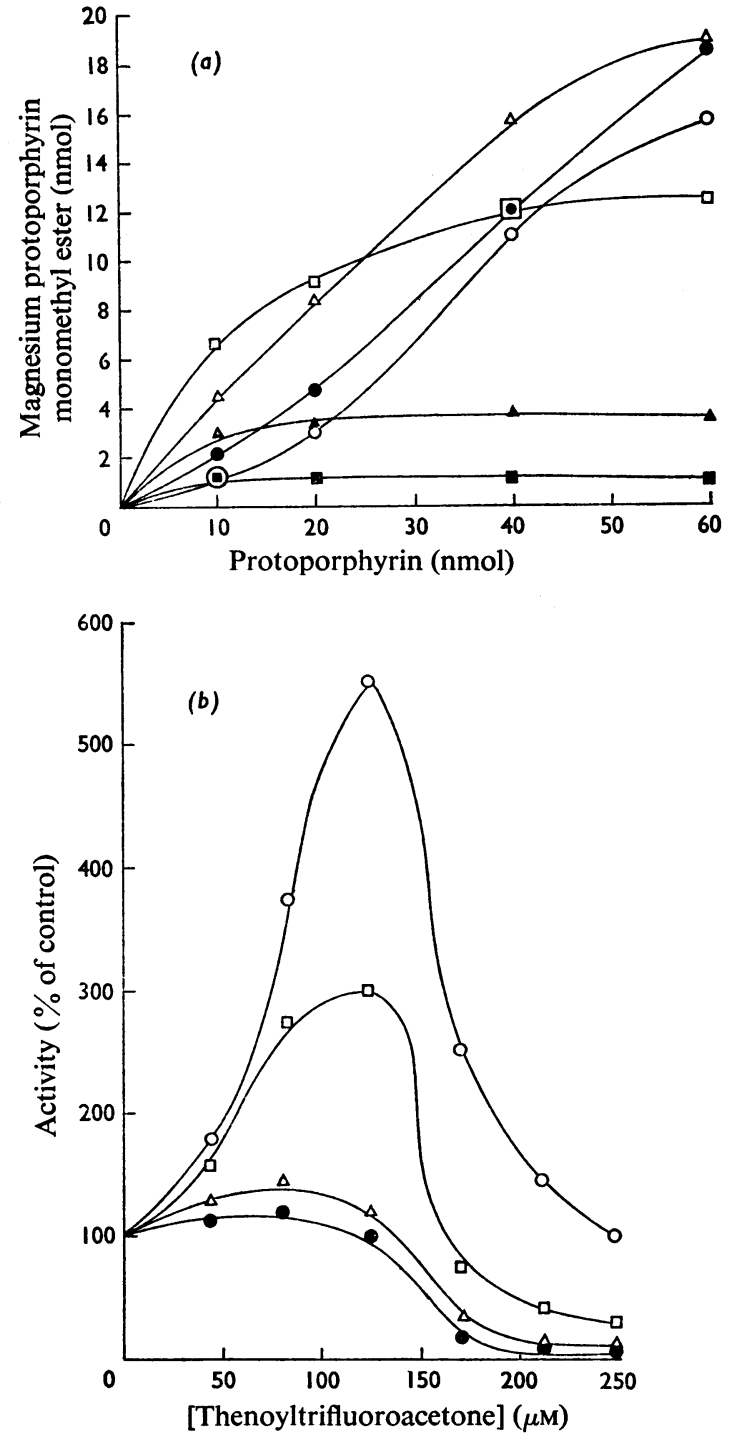

Fig. 2. Relation between the effect of thenoyltrifluoroacetone on magnesium chelatase activity and the substrate concentration

Different amounts of the lipid-protoporphyrin substrate $(200 \mathrm{nmol}$ of protoporphyrin $/ \mathrm{ml})$ were added to the assays as indicated. Lipid sol was added where appropriate so that each reaction mixture contained a total of $0.3 \mathrm{ml}$. The assays were done as previously described under anaerobic conditions in the light. (a) The concentrations of thenoyltrifluoroacetone were $(\mu \mathrm{M}): \circ, 0 ; \bullet, 40 ; \triangle, 80 ; \square, 125 ; \Delta, 165 ; \mathbf{n}, 250$. (b) The amounts of protoporphyrin in the assays were (nmol): $\odot, 10 ; \square, 20 ; \Delta, 40 ; \bullet, 60$. 
normal the S-shaped curve otherwise obtained. At low partial pressure of oxygen in the dark $\left(\mathrm{O}_{2}+\mathrm{N}_{2}\right.$; 5:95,) both Methyl and Benzyl Viologen inhibited.

Effect of intermediates and inhibitors of the tricarboxylic acid cycle. The effect of a number of intermediates of the tricarboxylic acid cycle and of related compounds on magnesium chelatase activity was determined. Citrate, $\alpha$-oxoglutarate, cis-aconitate, fumarate, succinate or malate, at a concentration of $2 \mathrm{mM}$, activated by up to $60 \%$ at low partial pressures of oxygen in the dark, but under anaerobic conditions in the light they were slightly inhibitory or without effect. Malonate ( $9 \mathrm{~mm}$ ) did not inhibit under any conditions, but stimulated by $25 \%$ at low partial pressure of oxygen in the dark. Fluoroacetate (20mM) inhibited by about $50 \%$ under low partial pressure of oxygen in the dark, but only slightly under anaerobiosis in the light.

Requirement for ATP other than for the synthesis of $S$-adenosylmethionine. It seemed possible that inhibition of magnesium chelation by the different inhibitors of electron and energy transfer was due to their preventing the synthesis of ATP. It is known that ATP is required for the synthesis of $S$-adenosylmethionine, which is essential for the methyl transferase reaction coupled with magnesium insertion into protoporphyrin (Gorchein, 1972). Exogenous magnesium protoporphyrin is readily methylated by whole cells (Gorchein, 1972) and methylation is not rate-limiting for the conversion of protoporphyrin into magnesium protoporphyrin methyl ester (Fig. 5). Thus, after $30 \mathrm{~min}$ with magnesium protoporphyrin as substrate, maximum conversion had taken place, whereas with protoporphyrin the activity was much less and the concentration of product increased for about $90 \mathrm{~min}$. It was found that inhibitors of electron and energy transfer did not significantly inhibit the methylation of magnesium protoporphyrin. Thus their mode of action was not due to their restriction of the availability of $S$-adenosylmethionine. It seems therefore that ATP has a function in magnesium chelation additional to its requirement in the synthesis of $S$-adenosylmethionine.
Uptake of protoporphyrin by whole cells. Protoporphyrin was not detected in $R$ ps. spheroides grown anaerobically in the light. However, protoporphyrin $(0.3-1.0 \mathrm{nmol} / 10 \mathrm{mg}$ dry wt.) was found in cells synthesizing magnesium protoporphyrin monomethyl

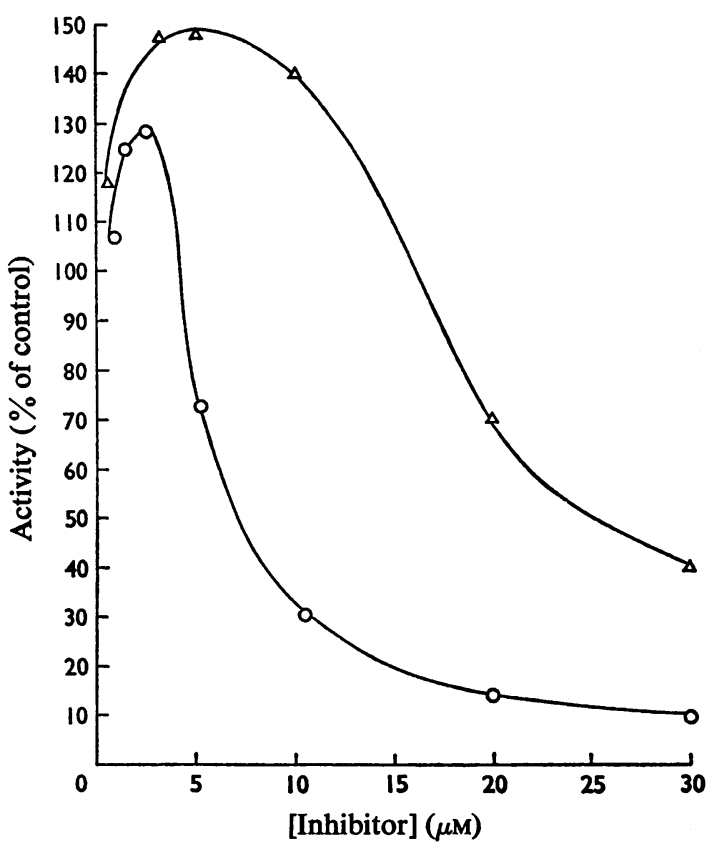

Fig. 3. Effect of tetramethyl-p-phenylenediamine and of $N$-methylphenazonium methosulphate on magnesium chelatase activity

The assays were done under anaerobic conditions in the light as described in the Materials and Methods section. The compounds added were: $\bigcirc, N$-methylphenazonium methosulphate; $\Delta$, tetramethyl-pphenylenediamine (for convenient graphical presentation concentrations of the latter are multiplied by 0.05).

Table 3. Effect of various quinones and vitamin $K$ analogues on magnesium chelatase activity

The assays were done as described in the Materials and Methods section. Compounds were added in $5 \mu l$ of ethanol.

\section{Compound added}

0.3 mM-2-Methyl-1,4-naphthaquinone

$0.2 \mathrm{~mm}$-2-Methyl-3-phytyl-1,4-naphthaquinone

$0.06 \mathrm{~mm}-2,3,5,6$-Tetramethyl-1,4-benzoquinone (duroquinone)

0.06mM-5-Hydroxy-1,4-naphthaquinone (juglone)

$0.1 \mathrm{~mm}$-Ubiquinone
Activity (\% of control)

$\begin{array}{cc}\text { Anaerobic/ } & \mathrm{O}_{2}+\mathrm{N}_{2} \\ \text { light } & (5: 95) / \text { dark } \\ 50 & 40 \\ 25 & 20 \\ 115 & 93 \\ 17 & 35 \\ 120 & 95\end{array}$

Vol. 134 
ester from exogenous protoporphyrin. These amounts remained unchanged or decreased with incubation times longer than $30 \mathrm{~min}$ and were lower still when the experiments were done in the presence of Methyl Viologen. When synthesis of magnesium protoporphyrin monomethyl ester was inhibited by the uncoupler carbonyl cyanide $m$-chlorophenylhydrazone or by antimycin A, or by anaerobic conditions in the dark, higher amounts of protoporphyrin were associated with the cells (Fig. 6). In these experiments the rates of uptake varied between 0.2 and $0.9 \mathrm{nmol} /$ min per $10 \mathrm{mg}$ dry wt. Even the lowest rate, however, would be sufficient for optimum synthesis of magnesium protoporphyrin monomethyl ester (approx. $0.2 \mathrm{nmol} / \mathrm{min}$ per $10 \mathrm{mg}$ dry wt. of cells; cf. Gorchein, 1972). The lack of magnesium chelatase activity under these conditions was therefore not due to inhibition of uptake of protoporphyrin. These results also appear to exclude the possibility that entry of protoporphyrin into the cells is dependent on active transport. The amounts of protoporphyrin associated with the cells were proportional to the amounts added to the incubation medium over the range $20-80 \mathrm{nmol}$, which is consistent with passive transport.

These permeability studies were technically difficult because protoporphyrin is not in true solution (as a monomer) in aqueous media except at extremes of pH. Although it was 'solubilized' in a lipid sol, it is likely that some precipitation took place during the incubations. It was necessary therefore to distinguish between any insoluble protoporphyrin outside the cells, which centrifuged down with them, and protoporphyrin bound intracellularly. It seemed possible

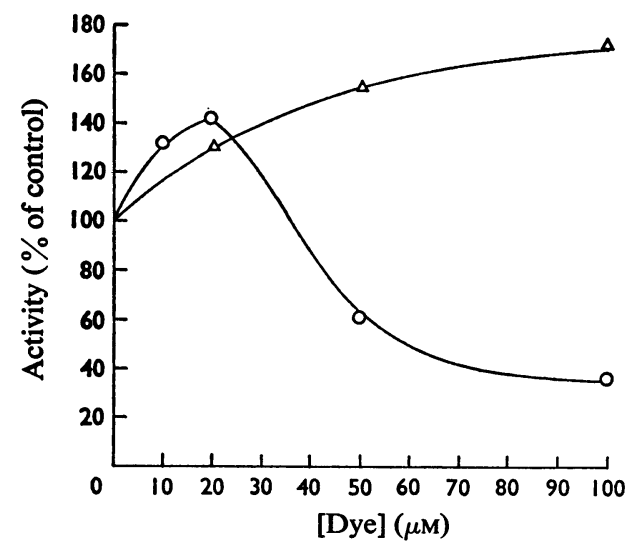

Fig. 4. Effect of Benzyl Viologen and Methyl Viologen on magnesium chelatase activity

The assays were done under anaerobic conditions in the light as previously described. $\bigcirc$, Benzyl Viologen; $\Delta$, Methyl Viologen.

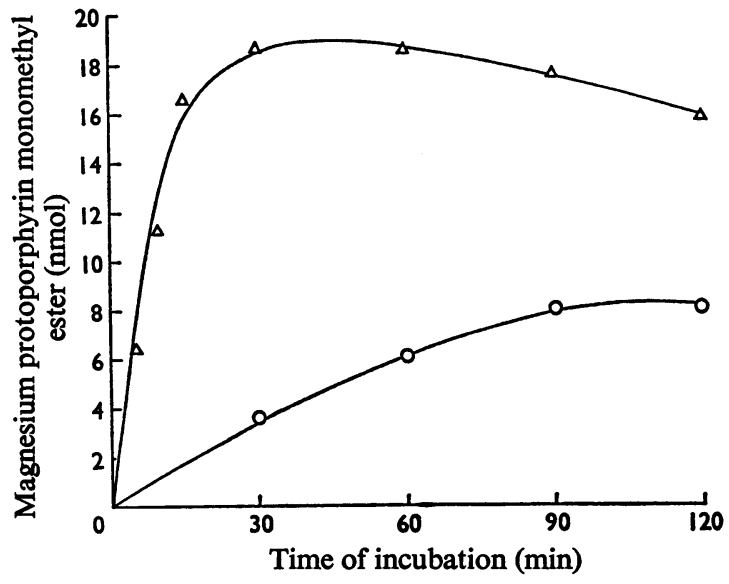

Fig. 5. Relation between time of incubation and amount of product formed

The assays of activities of magnesium protoporphyrin chelatase and $S$-adenosyl magnesium protoporphyrin methyl transferase in whole cells of Rhodopseudomonas spheroides were done under anaerobic conditions in the light as described in the Materials and Methods section. The substrates ( $40 \mathrm{nmol})$ were added in lipid sol: $\bigcirc$, protoporphyrin; $\Delta$, magnesium protoporphyrin.

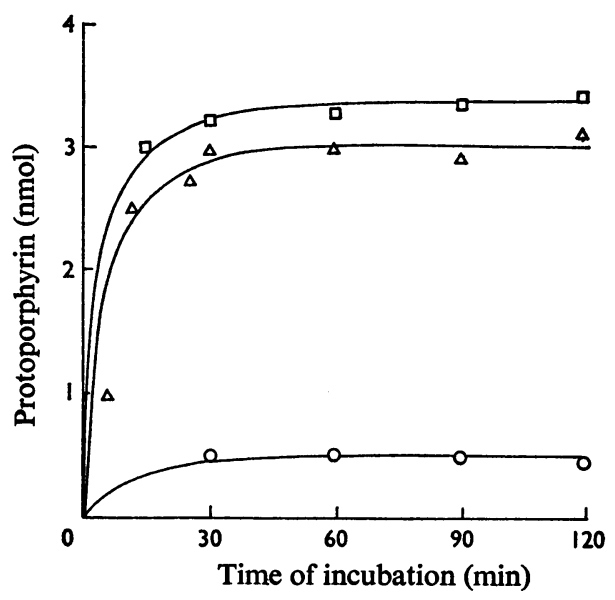

Fig. 6. Uptake of protoporphyrin by Rhodopseudomonas spheroides

The incubations were done under anaerobic conditions in the light without additions $(0)$ to the usual reaction mixture and with $50 \mu \mathrm{M}$-carbonyl cyanide $m$-chlorophenylhydrazone $(\Delta)$ and $50 \mu \mathrm{M}$-antimycin A ( $\square$ ). The protoporphyrin was extracted and determined as described in the Materials and Methods section. 


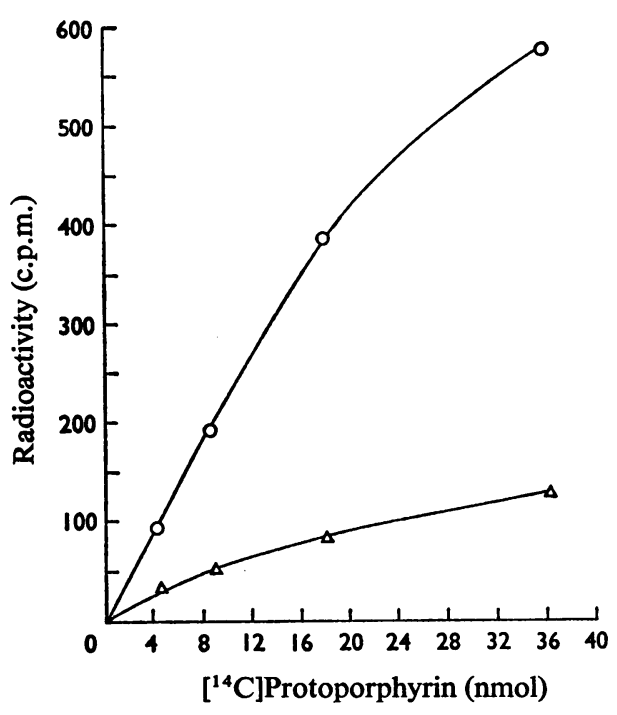

Fig. 7. Incorporation of exogenous protoporphyrin into bacteriochlorophyll

Assays with whole cells were done under the usual conditions but with $\left[{ }^{14} \mathrm{C}\right]$ protoporphyrin (sp. radioactivity 66c.p.m./nmol) as substrate. The reaction mixtures were then sonicated for $2 \mathrm{~min}$ to facilitate the complete extraction of the pigments. The twolightpetroleum extracts from each assay were pooled, washed thrice with $2 \mathrm{ml}$ portions of ion-free water, and the radioactivity was determined (c.p.m.) in a liquid-scintillation spectrometer, as previously described (Fig. 6 of Gorchein, 1972), in magnesium protoporphyrin monomethyl ester $(0)$ and in the light-petroleum phase $(\Delta)$.

that extracellular protoporphyrin would be removed selectively by a combination of differential centrifuging and by subsequent addition of lipid sol to redissolve it, whereas any internal protoporphyrin might not be so readily extracted. Uptake experiments were done as described under different conditions but with $\left[{ }^{14} \mathrm{C}\right]$ protoporphyrin $(40 \mathrm{nmol}$; sp. radioactivity 66 c.p.m./nmol). After the first centrifugation step, which removes a major proportion of the radioactive protoporphyrin, the pellets were taken up again in lipid sol containing non-radioactive protoporphyrin ( $40 \mathrm{nmol})$ and the 'washing' procedure in Ficoll-Tris was then followed as usual. The specific radioactivity of the protoporphyrin finally extracted was between 59 and $65 \mathrm{c} . \mathrm{p} . \mathrm{m} . / \mathrm{nmol}$ in different experiments. These results indicate that the protoporphyrin bound to the cells during the incubation does not exchange with protoporphyrin added afterwards.

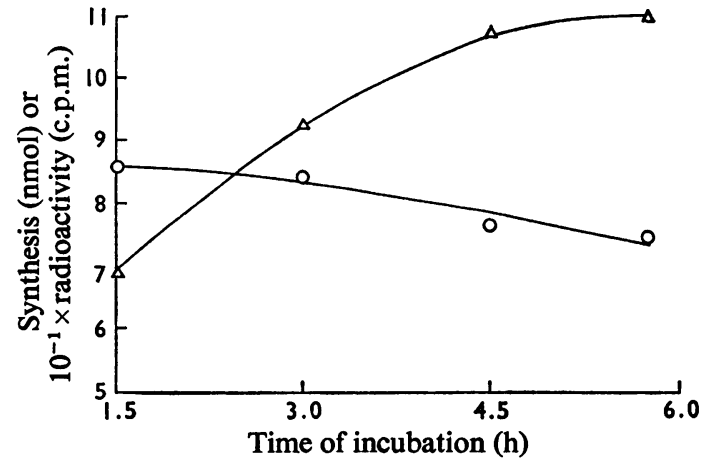

Fig. 8. Relation between time of incubation, synthesis of magnesium protoporphyrin monomethyl ester and incorporation of protoporphyrin into bacteriochlorophyll

$\mathrm{O}$, Magnesium protoporphyrin mono $\left[{ }^{14} \mathrm{C}\right]$ methyl ester (nmol); $\Delta, 10^{-1} \times$ radioactivity (c.p.m.) in the light-petroleum phase.

Incorporation of exogenous protoporphyrin and magnesium protoporphyrin monomethyl ester into bacteriochlorophyll

To determine what relation, if any, existed between the chelation of magnesium by protoporphyrin in this system where exogenous protoporphyrin is supplied, and the biosynthesis of bacteriochlorophyll, assays were set up with radioactive protoporphyrin. A significant proportion (generally about $10 \%$, but up to $19 \%$ in some experiments) of the protoporphyrin added was recovered in the light-petroleum phase during the extraction procedure (Fig. 7). With more prolonged incubation there was an increase in the incorporation of radioactivity into the light petroleum phase and a decrease in the amount of magnesium protoporphyrin monomethyl ester extracted (Fig. 8). Oxygen inhibited this incorporation of radioactivity (Table 4) to the same extent that it inhibited magnesium chelation (Fig. 9).

Thin-layer chromatography on $\mathrm{MN} 300$ cellulose with light petroleum (b.p. $40-60^{\circ} \mathrm{C}$ )-benzeneacetone $(4: 1: 0.5$, by vol.; Holden, 1962), followed by radioautography, showed that all the radioactivity in the light-petroleum phase corresponded to the position of bacteriochlorophyll, and it was well separated from a standard of magnesium protoporphyrin monomethyl ester. Chromatography on columns and on thin layers of polyethylene powder made up in and developed with acetone-water (70:30, v/v; Anderson \& Calvin, 1962) also gave clear separation of the different pigmented bands. The absorption spectrum of the blue-green pigment, extracted into ether by the addition of water, confirmed 
that it was bacteriochlorophyll. Nearly $80 \%$ of the radioactivity was eluted with this fraction.

The effect on this incorporation of some compounds which affected the synthesis of magnesium protoporphyrin monomethyl ester is shown in Table 5. Methyl Viologen increased the synthesis of magnesium protoporphyrin monomethyl ester, but markedly decreased the radioactivity incorporated into the light-petroleum phase. A similar but lesspronounced effect was obtained with puromycin, but 8-hydroxyquinoline inhibited both the magnesium chelation and the incorporation of radioactivity into the light-petroleum phase.

From these experiments it seemed likely that some magnesium protoporphyrin monomethyl ester synthesized from exogenous protoporphyrin was converted further either into bacteriochlorophyll itself or into late precursors which did not separate from it in either of the chromatographic systems used. This was directly confirmed by the finding that exogenous magnesium protoporphyrin monomethyl ester was also incorporated in high yield into the light-petroleum

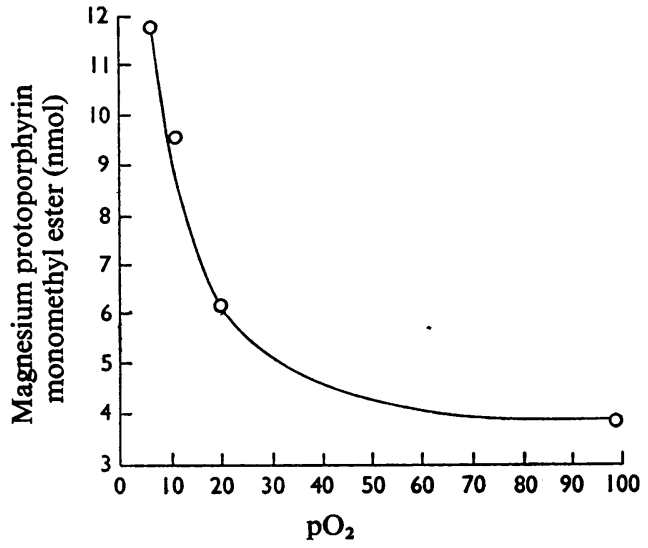

Fig. 9. Inhibition of magnesium chelatase by oxygen in the dark

The assays were done as described in the Materials and Methods section.

Table 4. Incorporation of $\left[{ }^{14} \mathrm{C}\right]$ protoporphyrin into light-petroleum phase at different partial pressures of oxygen in the dark

Each assay contained $24 \mathrm{nmol}$ of $\left[{ }^{14} \mathrm{C}\right]$ protoporphyrin (sp. radioactivity $66 \mathrm{c} . \mathrm{p} . \mathrm{m} . / \mathrm{nmol}$ ) and was done as described in the Materials and Methods section. Incubation was in the dark for $2 \mathrm{~h}$ with mixtures of $\mathrm{O}_{2}+\mathrm{N}_{2}$. Radioactivity was determined in a liquid-scintillation spectrometer as described previously (see Fig. 6 of Gorchein, 1972).

Radioactivity in light-petroleum phase

$\begin{array}{cccc}\text { Assay no. } & \mathrm{O}_{2}(\%) & \overbrace{\text { (c.p.m.) }} & \text { (\% of c.p.m. in assay no. 1) } \\ 1 & 5 & 309 & 100 \\ 2 & 10 & 162 & 52 \\ 3 & 20 & 102 & 33 \\ 4 & 100 & 48 & 15\end{array}$

Table 5. Incorporation of protoporphyrin into 'bacteriochlorophyll' in the presence of compounds altering the synthesis of magnesium protoporphyrin monomethyl ester

Each assay contained $24 \mathrm{nmol}$ of $\left[{ }^{14} \mathrm{C}\right]$ protoporphyrin (sp. radioactivity $66 \mathrm{c} . \mathrm{p} . \mathrm{m}$./nmol). The incubations were done under anaerobic conditions in the light as indicated in the Materials and Methods section. The products were isolated and determined as described in the legend to Fig. 7. The quantity of 'bacteriochlorophyll' synthesized was obtained by dividing the radioactivity (c.p.m.) incorporated into the washed light-petroleum phase by the specific radioactivity of the $\left[{ }^{14} \mathrm{C}\right]$ protoporphyrin.

Tube no.

Additions

1 None

2 2mM-Methyl Viologen

$3 \quad 0.5 \mathrm{~mm}$-Puromycin

4 4mm-8-Hydroxyquinoline

5 Methyl Viologen + puromycin

6 8-Hydroxyquinoline + Methyl Viologen
Magnesium protoporphyrin monomethyl ester (nmol/assay)

\section{8}

9.5

6.2

2.7

10.0

1.9
'Bacteriochlorophyll'

(c.p.m. in light (nmol/ petroleum) assay)

$\begin{array}{rr}239 & 3.62 \\ 30 & 0.45 \\ 172 & 2.60 \\ 16 & 0.24 \\ 26 & 0.39 \\ 16 & 0.24\end{array}$




\section{Table 6. Incorporation of magnesium protoporphyrin mono $\left[{ }^{14} \mathrm{C}\right]$ methyl ester into bacteriochlorophyll}

The assay and extractions were done as described previously. Incubation was under anaerobic conditions in the light for $90 \mathrm{~min}$. The substrate, $6.8 \mathrm{nmol}$ of magnesium protoporphyrin mono $\left[{ }^{14} \mathrm{C}\right]$ methyl ester (sp. radioactivity 1500 c.p.m./nmol), was isolated from assays done in the usual manner but with the addition of substrate amounts of $\mathrm{L}-\left[\mathrm{Me}^{-14} \mathrm{C}\right]$ methionine, and was added in lipid sol. Radioactivity was determined in a Nuclear-Chicago liquidscintillation spectrometer, as previously described (see the legend to Fig. 7).

Ether phase

$\overbrace{\begin{array}{c}\text { Magnesium protoporphyrin } \\ \text { monomethyl ester (nnol) }\end{array}}$

5.3
Radioactivity
(c.p.m.)

6720
Light-petroleum phase

$\begin{array}{cc}\begin{array}{c}\text { Radioactivity } \\ \text { (c.p.m.) }\end{array} & \begin{array}{c}\text { Substrate incorporated } \\ \text { (c.p.m. } / 1500=\text { nmol) }\end{array} \\ 3060 & 2.0\end{array}$

phase (Table 6), and on chromatography on polyethylene the radioactivity was eluted in a manner similar to that found when $\left[{ }^{14} \mathrm{C}\right]$ protoporphyrin was the substrate. Oxygen did not inhibit this incorporation.

\section{Discussion}

\section{Requirement for electron and energy transfer for acti-} vity of magnesium-protoporphyrin chelatase

Uncouplers and oligomycin inhibited magnesium chelation under all environmental conditions. There was therefore not only a requirement for energy, but more precisely for the synthesis or utilization of ATP, which is specifically blocked by oligomycin (Lardy et al., 1958). All the inhibitors of electron or hydrogen transport known to act at phosphorylation sites (Scheme 1) inhibited oxygen uptake and magnesium chelation to the same extent at low partial pressure of oxygen in the dark. However, only antimycin A and 2-heptyl-4-hydroxyquinoline $\mathrm{N}$-oxide inhibited magnesium chelation under both aerobic and photosynthetic conditions. It seemed likely therefore that the inhibition of magnesium chelation under aerobic conditions was related to respiratory inhibition and that under anaerobic conditions in the light the reaction was not dependent on pathways of hydrogen or electron transfer blocked by Amytal, rotenone, azide and cyanide. Although the concentration of antimycin A required, $30 \mu \mathrm{M}$ for about $50 \%$ inhibition, was much greater than that which inhibits mitochondrial electron transport (about $10^{-9} \mathrm{M}$ ), it represents moderate sensitivity for bacteria (e.g. Straat \& Nason, 1965). Electron transfer between a $b$-type and a $c$-type cytochrome coupled to the synthesis or utilization of ATP would therefore appear to be essential under all environmental conditions for the magnesium-chelation reaction. Consistent with this interpretation is the finding that although $N N N^{\prime} N^{\prime}$ tetramethyl- $p$-phenylenediamine dihydrochloride, which allows electrons to by-pass the site blocked by antimycin, restored oxygen uptake, it did not restore magnesium chelation. This mechanism of activation of the enzyme implies that the cytochrome $b$ and $c$ components involved are common to both the 'respiratory' and 'photosynthetic' electron-transport chains. The existence of common components is supported by the well-known observation (e.g. Van Niel, 1941) that light inhibits oxygen uptake by pigmented cells. Suspensions of Rps. spheroides in the Tris buffer-chelator mixture of the present experiments also showed immediate and complete inhibition of oxygen uptake on illumination in the oxygen electrode. In addition, the effect of light was abolished by the uncouplers. Control of adaptation from growth under aerobic to photosynthetic conditions by the redox state of components of the electron-transport chain (Cohen-Bazire et al., 1957) may be effected by activation of the magnesium-chelation reaction in the manner suggested above.

The inhibition by Amytal and rotenone suggested that oxidation of NADH was required at low partial pressure of oxygen in the dark. This was supported by the finding that intermediates of the tricarboxylic acid cycle whose oxidation was coupled with the generation of NADH stimulated and that fluoroacetate inhibited. The role of hydrogen transfer from succinate was more difficult to evaluate. Although malonate did not inhibit the activity of magnesium chelatase, thenoyltrifluoroacetone, which blocks electron transport in mitochondria, probably by chelating non-haem iron in the succinate dehydrogenase-flavoprotein complex (Redfern et al., 1965), inhibited under both respiratory and photosynthetic conditions at concentrations far lower than were required to demonstrate inhibition of oxygen uptake. The effects of this compound, however, were complex and it may have had a direct action on the enzyme.

The stimulation or inhibition of magnesium chelation by the different quinones and artificial electron donors or acceptors cannot be unequivocally explained. Interaction with flavoproteins, the formation of hydrogen peroxide and by-passes of electron transport are all possibilities. Methyl Viologen and duroquinone had similar properties of stimulating markedly and of making 'normal' the kinetics of the 


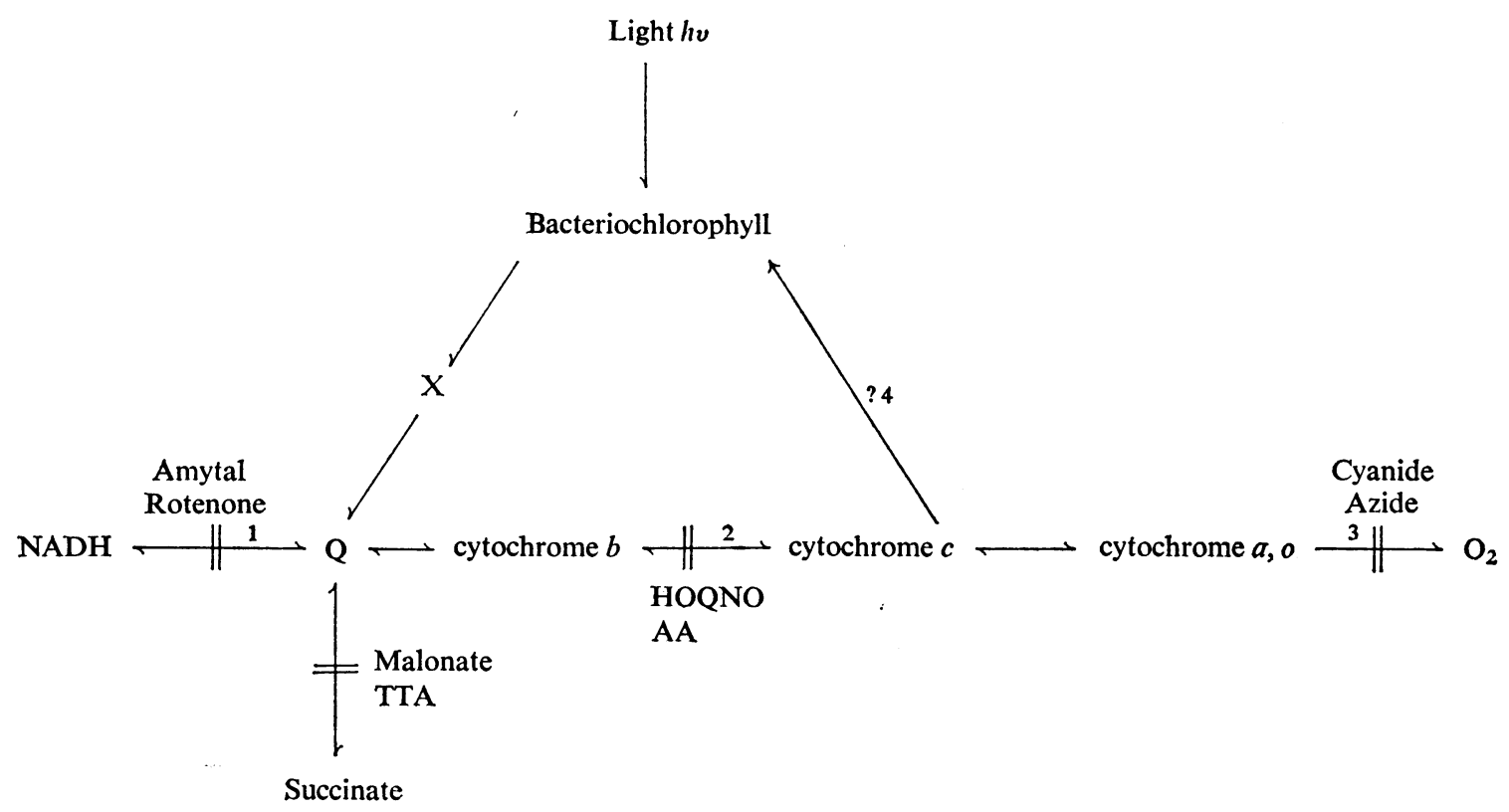

Scheme 1. Electron-transport system in Rhodopseudomonas spheroides

The sites of inhibition are indicated by double lines and of phosphorylation by numbers (1-4). For simplicity, only one cytochrome $b \rightarrow$ cytochrome $c$ segment of electron transport is shown, but there are likely to be separate, interacting chains for the 'cyclic' (photosynthetic) and respiratory pathways (see reviews by Vernon, 1968; Frenkel, 1970 ; Klingenberg, 1968). The principal $c$-type cytochrome is $c_{2} . \mathrm{X}$ is the unidentified primary electron acceptor. Abbreviations: TTA, thenoyltrifluoroacetone; HOQNO, 2-heptyl-4-hydroxyquinoline $N$-oxide; AA, antimycin A.

substrate curve under anaerobic conditions in the light. These compounds could thus be of value to increase the sensitivity of the assay.

The possibility that changes in the permeability of the cells during adaptation from aerobic to photosynthetic growth accounted for differences in the amount of magnesium chelated was considered previously (Gorchein, 1972). The entry of protoporphyrin into the pigmented cells of the present experiments was shown above not to be prevented by inhibitors of electron and energy transfer. Some caution, however, may still be required in interpreting these uptake experiments because of the insolubility of protoporphyrin in aqueous media.

Incorporation of exogenous protoporphyrin into bacteriochlorophyll or late precursors and into haem

Exogenous protoporphyrin and also magnesium protoporphyrin monomethyl ester were converted into compounds extractable into light petroleum from acetone-ammonia. These compounds were not rigorously identified, but it seemed likely from their chromatographic properties that the major product was bacteriochlorophyll, with perhaps small amounts of late intermediates. Magnesium protoporphyrin, although not directly shown to be converted into these compounds, is also likely to be a substrate, since it became methylated in high yield in the system described. The incorporation of radioactivity from $\left[{ }^{14} \mathrm{C}\right]$ protoporphyrin into the light petroleum phase was inhibited by oxygen, which also inhibited to about the same extent the synthesis of magnesium protoporphyrin monomethyl ester. The failure to obtain complete inhibition, even with pure oxygen, was probably because the cells did not equilibrate rapidly with the gaseous phase. There was, however, no inhibition of the incorporation of magnesium protoporphyrin monomethyl ester. The insertion of magnesium therefore appears to be the only step in the biosynthetic sequence between protoporphyrin and bacteriochlorophyll that is inhibited by oxygen.

The synthesis of magnesium protoporphyrin monomethyl ester was increased by adding Methyl Viologen or puromycin to the assay, whereas the synthesis of later intermediates was inhibited. These different effects may be related in part to inhibition of protein synthesis required for the biosynthesis of 
bacteriochlorophyll but not, as discussed previously (Gorchein, 1972), for magnesium protoporphyrin monomethyl ester. In a complex system such as this, however, there are other possibilities. For example, large quantities of haem were also synthesized from $\left[{ }^{14} \mathrm{C}\right]$ protoporphyrin in some of the assays (unpublished results), and this reaction introduces yet another variable, if only by competing for the available protoporphyrin substrate.

These results demonstrate that exogenous protoporphyrin and magnesium protoporphyrin monomethyl ester can be incorporated into bacteriochlorophyll. Despite its limitations the assay system described may provide a method for investigating late steps in the biosynthesis of bacteriochlorophyll. Its application to studies with mutants may be particularly rewarding.

I thank Mr. R. Smither and Dr. P. J. Watt of the Department of Bacteriology, St. Mary's Hospital Medical School, for allowing me to use the Coulter counter and Braun shaker respectively, and Dr. G. H. Tait for help during the preparation of the manuscript.

\section{References}

Anderson, A. F. H. \& Calvin, M. (1962) Nature (London) 194, 285-286

Cohen-Bazire, G., Sistrom, W. R. \& Stanier, R. Y. (1957)

J. Cell. Comp. Physiol. 49, 25-68
De Matteis, F. \& Prior, B. E. (1962) Biochem. J. 83, 1-8

Falk, J. E. (1964) Porphyrins and Metalloporphyrins, p. 170, Elsevier Publishing Co., Amsterdam, London and New York

Frenkel, A. W. (1970) Biol. Rev. 45, 569-616

Gibson, K. D., Neuberger, A. \& Tait, G. H. (1963) Biochem. J. 88, 325-334

Gorchein, A. (1972) Biochem. J. 127, 97-106

Holden, M. (1962) Biochim. Biophys. Acta 56, 378-379

Kehl, R. \& Stich, W. (1951) Hoppe-Seyler's Z. Physiol. Chem. 289, 6-10

Klingenberg, M. (1968) in Biological Oxidations (Singer, P., ed.), pp. 3-54, Interscience, New York

Klingenberg, M. \& Pfaff, E. (1967) in Methods Enzymol. 10, 680-684

Lardy, H. A., Johnson, D. \& McMurray, W. C. (1958) Arch. Biochem. Biophys. 78, 587-597

Lee, C.-P., Nordenbrand, K. \& Ernster, L. (1965) in Oxidases and Related Redox Systems (King, T. E., Mason, H. S. \& Morrison, M. eds.), vol. 2, pp. 960-981, John Wiley and Sons, New York, London and Sydney

Onisawa, J. \& Labbe, R. F. (1963) J. Biol. Chem. 238, 724-727

Redfern, E. R., Whittaker, P. A. \& Burgos, J. (1965) in Oxidases and Related Redox Systems (King, T. E., Mason, H. S. \& Morrison, M. eds.), vol. 2, pp. 944-948, John Wiley and Sons, New York, London and Sydney

Straat, P. \& Nason, A. (1965) J. Biol. Chem. 290, 14121426

Van Niel, C. B. (1941) Advan. Enzymol. Rel. Subj. Biochem. 1, 263-328

Vernon, L. P. (1968) Bacteriol. Rev. 32, 243-261 